\title{
DAKWAH PADA MASA UMAR BIN KHATTAB
}

\author{
Patmawati
}

\begin{abstract}
ABSTRAK
Umar memerintah selama sepuluh tahun (634-644 M). Masa jabatannya berakhir dengan kematian. Abu Bakar menunjuk Umar sebagai penggantinya, walaupun perbuatan ini belum pernah dilakukan oleh Nabi. Kepribadian yang tegas, otoriter, tetapi berkeadilan, kereligiusannya tidak diragukan, dan orator ulung dimana ceramahnya dapat dilihat dalam buku Pidato-pidato Umar. Kehebatan Umar bin Khattab terlihat dalam mengkonsolidasikan negeri-negeri yang telah ditaklukkannya. la berhasil mempersatukan beberapa suku yang ada di Arab tanpa memandang ras dan suku sehingga terciptalah peradaban yang maju pada waktu itu. Umar bin Khattab Berpidato di dalam mesjid, sesudah memanjatkan puji syukur kepada Allah, Umar mengajak dan menganjurkan umat Islam untuk berjihad. Inilah yang menjadi kekuatan dasar muslim dalam menghadapi musuhnya. Umar sebagai pemimpin mampu membakar semangat para mujahid. Pemimpin seperti inilah yang tetap hidup dalam hati setgiap muslim dahulu dan sekarang.
\end{abstract}

Kata Kunci: kepemimpinan, muslim tangguh, metode dakwah

\section{A. Pendahuluan}

$\begin{array}{ccc}\text { Abu } & \text { Bakar menjadi khalifah } \\ \text { selama } & \text { dua tahun lebih, }\end{array}$
kepemimpinannya begitu singkat tetapi dia telah meletakkan pondasi yang kuat dalam penegakan ajaran Islam. Ketegasan Abu Bakar dalam menghadapi kaum murtad, orang-orang yang tak mau bayar zakat, menulis dan mengumpulkan al-Quran dalam bentuk mushab atas inisiatif Umar bin Khattab, serta melaksanakan ekspansi ke luar jazirah Arab, sebagai cikal bakal perluasan wilayah Islam.

Kepemimpinan Abu Bakar digantikan oleh Umar bin Khattab, kekuasaan Islam semakin memperlihatkan geliatnya. Banyak perubahan yang terjadi pada masa Umar bin Khattab. Islam bukan hanya sebagai agama ritual, melainkan juga kekuatan baru di Negara Arab, khususnya Mekah dan Madinah. Luasnya penaklukan pada era kepemimpinan Umar bin Khattab mencapai 2251030 mil. Secara teologis, 
kejayaan Islam pada masa Umar bin Khattab tidak terlepas dari keinginan Rasulullah saw untuk mempunyai pemuda gagah berani yang bisa mengalahkan kafir Quraisy dalam doanya, sebagaimana dikutip oleh Ahmad Hatta, dkk (2011: 151)., dari hadis yang diriwayatkan oleh Tirmidzi: "Ya Allah, kukuhkanlah Islam ini dengan salah satu dari dua orang yang paling Engkau cintai: Umar bin Khattab atau Abu Jahal bin Hisyam. Ternyata, yang paling dicintai oleh Allah adalah Umar."

Dalam menjalankan roda pemerintahan Umar terkesan diktator, keras, ketat, dan tidak kenal kompromi, namun tegas dan berkeadilan. Umar bin Khattab dikenal juga sebagai khalifah yang berwibawa, sederhana, dan merakyat. Dia sering berjalan-jalan ke pelosok desa seorang diri dan melarang anggota keluarganya berfoya-foya. Literatur Arab sarat dengan berbagai peristiwa yang memuji watak keras Umar. la diriwayatkan menghukum mati anaknya sendiri karena mabuk-mabukan dan berperilaku amoral (Philip K. Hitt, 2005: 219).

Umar bin Khattab telah mengubah dunia Islam menjadi berperadaban yang tinggi dan berarti bagi kemajuan Islam khususnya dan dunia Barat pada umumnya. Hal ini menjadi bukti bahwa Umar bin Khattab telah mengaplikasikan yang telah diajarkan oleh Rasulullah saw tentang Islam yang ideal pasca-Perjanjian Hudaibiyah $^{1}$ (Badri Yatim, 1993: 30 dan Patmawati, 2014: 16) dan Piagam Madinah $^{2}$ (Wahyu llahi dan Harjani Hefni, 2007: 59 dan A. Syalabi, 2003: 104) sebagai pengejawantahan konsep

${ }^{1}$ Isi Perjanjian Hudaibiyah antara lain: 1) Kaum muslimin belum boleh mengunjungi Ka'bah tahun ini tetapi ditangguhkan sampai tahun depan. 2) Lama kunjungan dibatasi sampai tiga hari saja. 3) Kaum muslimin wajib mengembalikan orang-orang Mekah yang melarikan diri ke Madinah, sedang sebaliknya, pihak Quraisy tidak harus menolak orang-orang Madinah yang kembali ke Mekah. 4) Selama sepuluh tahun diberlakukan genjatan senjata antara masyarakat Madinah dan Mekah. 5) Tiap kabilah yang ingin masuk ke dalam persekutuan kaum Quraisy atau kaum Muslimin, bebas melakukannya tanpa mendapat rintangan.

2 Isi perjanjian Piagam Madinah antara lain: 1) Kaum muslimin dan kaum Yahudi hidup secara damai, bebas memeluk dan menjalankan ajaran agamanya masing-masing. 2) Orangorang Yahudi berkewajiban memikul biaya mereka sendiri, dan kaum muslimin wajib memikul biaya mereka sendiri. 3) Apabila salah satu pihak diperangi musuh, maka mereka wajib membantu pihak yang diserang. 4) Di antara mereka saling mengingatkan, dan saling berbuat kebaikan, serta tidak akan saling berbuat kejahatan. 5) Kaum muslimin dan Yahudi wajib saling menolong dalam melaksanakan kewajiban untuk kepentingan bersama. 6) Bumi Yastrib menjadi tanah suci karena naskah perjanjian ini. 7) Nabi Muhammad adalah pemimpin umum untuk seluruh penduduk Madinah. Bila terjadi perselisihan di antara kaum muslimin dengan kaum Yahudi, maka penyelesaiannya dikembalikan kepada Nabi sebagai pemimpin tertinggi di Madinah. 
dasar Negara Islam ideal pada era Nabi Muhammad saw.

Pada era Umar bin Khattab, secara keseluruhan tidak ada kekacauan yang berarti. Bahkan sebaliknya, Islam menjadi besar dan gemilang di puncak kepemimpinannya. la berhasil mempersatukan beberapa suku yang ada di Arab tanpa memandang ras dan suku sehingga terciptalah peradaban yang maju pada waktu itu $(\mathrm{H}$. Sulasman, 2013: 78). Oleh karena itu, dalam makalah ini akan dibahas: Biografi Umar bin Khattab, langkah-langkah kebijakan Khalifah Umar bin Khattab, Penataan Birokrasi Pemerintahan, mengembangkan ilmu pengetahuan dan pendidikan agama Islam, ijtihad Umar bin Khattab.

\section{B. Biografi Umar bin Khattab}

Umar bin Khattab dilahirkan di Mekah (Jamil Ahmad, 2000: 21), nama lengkap Umar bin Khattab adalah Umar bin Abdul Uzza bin Rabbah bin Abdullah bin Qurt Razzah bin Adiy bin Ka'ab bin Luay. la dilahirkan setelah tiga belas tahun kelahiran Nabi Muhammad saw. (H. Sulasman, 2013: 79 dan Muhammad Ahmad Asyur, 1997: 19) Ayahnya bernama Khattab bin Nufail al-Quraisy. Silsilahnya berkaitan dengan garis keturunan Nabi pada generasi kedelapan Ka'ab bin Lu'ay. Ibunya bernama Hantamah binti Hasyim bin Mugirah bin Abdullah bin Amr bin Mahzum (H. Sulasman, 2013: 79) . Moyangnya memegang jabatan duta besar dan leluhurnya adalah pedagang. la salah satu dari 17 orang Mekah yang terpelajar ketika kenabian dianugerahkan kepada Nabi Muhammad saw. (Jamil Ahmad, 2000: 21).

Umar dikenal sebagai orang yang menjaga kehormatan dirinya dan memiliki watak yang temperamental. Setiap kali ia berpapasan dengan orangorang muslim, pasti dia menimpakan berbagai macam siksaan. Dalam hati Umar bergolak berbagai perasaan yang sebenarnya saling bertentangan. Penghormatannya terhadap tradisitradisi leluhur, kebebasan menenggak minuman keras hingga mabuk dan bercanda ria, bercampur baur dengan ketakjubannya terhadap ketabahan dan kesabaran orang-orang muslim dalam menghadapi cobaan dalam rangka mempertahankan akidahnya. Keadaan ini masih ditambah lagi dengan keraguraguan yang menari di dalam benaknya, dan benak siapa pun yang berakal, bahwa apa yang diserukan Islam jauh lebih bagus dan agung daripada apa yang dilakukan oleh mereka selama ini (Syaikh Shaifurrahman Al-Mubarakfury, 2005: 138). 
Keislaman Umar di awali dengan peristiwa Umar yang ingin membunuh Nabi Muhammad saw. Nabi pada saat itu sedang berkumpul dengan sahabatsahabatnya yang tidak hijrah ke Abisinia (Ethopia), di rumah Arqam di Safa. Di antara mereka ada Hamzah, Ali bin Abi Thalib, Abu Bakar dan muslimin yang lain. Pertemuan mereka ini diketahui Umar. la pun pergi ke tempat mereka, ia mau membunuh Nabi. Dengan maksud, kematian Nabi dapat mengembalikan orang-orang yang hijrah ke Abisinia akan kembali bersatu dengan suku Quraisy yang ada di Mekah, setelah mengalami perpecahan. Di tengah perjalanan ia bertemu dengan Nu'aim bin Abdullah. Setelah mengetahui maksudnya, Nu'aim berkata:

"Umar, Anda menipu diri sendiri. Anda kira keluarga Abdul Manaf akan membiarkan anda merajalela begini sesudah membunuh Muhammad? Tidakkah lebih baik pulang saja ke rumah dan perbaiki keluargamu sendiri? (Muhammad Husain Haekal, 2011: 114) sesungguhnya Fatimah, adik perempuanmu dan suaminya, Sa'id bin Zaid juga telah menjadi pengikut Muhammad dan meninggalkan agama mereka berdua sekarang ini" (Ahmad Hatta, 2011: 153).

Umar ke rumah Fatimah dengan terburu-buru, yang saat itu Khabbab bin
Al-Art, ada di rumah Fatimah sedang menghadapi Shahifah berisi surat Thaha. Dia membacakan surat ini di hadapan Fatimah dan Sa'id bin Zaid. Tatkala Habbab mendengar suara kedatangan Umar, dia menyingkir ke bagian belakang ruangan, sedangkan Fatimah menyembunyikan Shahifah alQuran. Namun tatkala mendekati rumah adiknya tadi, Umar sempat mendengar bacaan Khabbab di hadapan adik dan iparnya (Syaikh Shaifurrahman AlMubarakfury, 2005: 140).

Umar sangat marah dan langsung memukul iparnya dengan ganas, pukulan yang tidak membuat sang ipar dan adiknya meninggalkan agama Islam. Keteguhan adik dan iparnya membuat Umar meminta mereka membaca kembali kitab suci-Quran. Permintaan tersebut dipenuhi. Kandungan arti dan alunan ayat-ayat Kitabullah ternyata membuat Umar begitu terpesona, sehingga ia bergegas ke rumah Nabi dan dan langsung memeluk agama Islam (Jamil Ahmad, 2000: 21).

Umar masuk Islam membuat kekuatan agama Islam semakin tangguh. la kemudian menjadi penasehat utama Abu Bakar selama masa pemerintahan 2 tahun lebih. Ketika Abu Bakar meninggal maka kekhalifahan dilanjutkan oleh Umar bin Khattab. 
Pengangkatan Umar bin Khattab menjadi khalifah dilakukan melalui penunjukkan oleh Abu Bakar.

Ketika Abu Bakar sakit, sahabat berkumpul di sekitarnya. Abu Bakar bertanya kepada mereka:

"Apakah kalian akan menerima orang yang saya akan calonkan sebagai pengganti saya? Saya bersumpah bahwa saya melakukan yang terbaik dalam menentukan hal ini, dan saya telah memilih Umar ibn Al-Khattab sebagai pengganti saya."

Para sahabat menjawab:

"Kami mendengarnya dan kami akan mentaatinya" (Jaih Mubarok, tt., 74).

Abu Bakar menunjuk Umar sebagai penggantinya, walaupun perbuatan ini belum pernah dilakukan oleh Nabi. Menurut Abd al-Wahhab alNajjar ikutip oleh Jaih Mubarok (Jaih Mubarok, tt., 103) ketika Rasul saw wafat, umat Islam terbagi menjadi dua kelompok dan menetapkan bahwa pemimpin mesti berasal dari kelompoknya. Hal itu terjadi karena Nabi saw. Tidak menentukan penggantinya sebelum wafat. Apabila Abu Bakar membiarkan kursi khilafah (kepemimpinan) kosong ketika ia meninggal, maka umat Islam diperkirakan akan kembali pada perdebatan sebagai terjadi di Saqifah Bani Sa'idah.

Hal serupa dikemukan juga oleh Jalal al-Din al-Suyuthi bahwa kekosongan pemimpin akan melahirkan fitnah yang lebih parah dan lebih dahsyat dibandingkan dengan adanya fitnah dari orang-orang murtad. Dengan kata lain, Abu Bakar menunjuk Umar sebagai penggantinya dalam memimpin umat Islam agar umat Islam terhindar dari perpecahan (Jaih Mubarok, tt., 103). Penunjukan Umar sebagai pengganti Abu Bakar sangat tepat karena bertepatan dengan pengembangan wilayah dakwah keluar dari Jazirah Arab melalui penaklukan wilayah.

Umar memerintah selama sepuluh tahun (634-644 M). Masa jabatannya berakhir dengan kematian. Dia dibunuh oleh seorang budak dari Persia, agama Nasrani bernama Abu Lu'lu'ah. Dia ditawan oleh tentara Islam di Nahawand, dan kemudian menjadi hamba sahaya Mughirah ibnu Syu'bah. Umar bin Khattab telah merobohkan kerajaan Persia dan melenyapkan kekuasaan mereka. Hal ini menyebabkan lapisan atas dari bangsa Persia beserta pendukungpendukungnya menaruh dendam terhadap Umar dan membunuhnya. Pembunuhan direncanakan oleh tiga 
serangkai, yaitu: Hurmuzan, ${ }^{3}$ Jufainah ${ }^{4}$ (A. Syalabi, 2003: 227) dan Abu Lu'luah.

Untuk menentukan penggantinya. Umar tidak menempuh jalan yang dilakukan Abu Bakar. Dia menunjuk enam orang sahabat, yakni Usman bin Affan, Ali bin Abi Thalib, Zubair bin Awwam, Talhah bin Ubaidillah, Abdurrahman bin Auf dan Sa'ad bin Abi meminta kepada mereka untuk memilih salah seorang diantara mereka untuk menjadi khalifah sebagai penggantinya.

\section{Dakwah Umar Melalui Penaklukan}

Penaklukan wilayah pada masa Umar bin Khattab dimulai dari ibu kota Syiria, Damaskus, dikuasai pada tahun $635 \mathrm{M}$ dan setahun kemudian, setelah tentara Bizantium kalah dipertempuran Yarmuk, seluruh daerah Syria jatuh ke bawah kekuasaan Islam. Dengan memakai Syiria sebagai basis, penaklukan diteruskan ke Mesir di bawah pimpinan Amr ibn Ash dank e Irak di bawah pimpinan Sa'ad ibn Abi Waqqash. Iskandariah, ibu kota Mesir, ditaklukkan 641 M. dengan demikian,

\footnotetext{
3 Seorang pembesar bangsa Persia, yang telah kehilangan kekuasaan dan kedudukan, dan karena tidak ada harapannya lagi untuk mengembalikan kekuasaan dan kedudukannya itu, terpaksalah ia hidup sebagai seorang yang biasa saja.

${ }^{4}$ Penganut agama Nasrani, ia berasal dari Hirah, dan bekerja mengajar menulis dan membaca di Madinah.
}

Mesir jatuh ke bawah kekuasaan Islam. Al-Qadisiyah, sebuah kota dekat Hirah di Iraq, jatuh pada tahun $637 \mathrm{M}$. dari sana serangan dilanjutkan ke ibu kota Persia. Al-Madain yang jatuh pada tahun itu juga. Pada tahun $641 \mathrm{M}$, Mosul dapat dikuasai. Dengan demikian, pada masa kepemimpinan Umar, wilayah kekuasaan Islam sudah meliputi Jazirah Arabia, Palestina, Syiria, sebagian besar wilayah Persia, dan Mesir. Secara administrasi pemerintahan diatur menjadi delapan wilayah propinsi: Mekkah, Madinah, Syiria, Jazirah, Basrah, Kufah, Palestina, dan Mesir (Badri Yatim, 1993: 37).

Kehebatan Umar bin Khattab terlihat dalam mengkonsolidasikan negeri-negeri yang telah ditaklukkannya. Para orientalis Barat menyatakan bahwa kemenangan Islam pada waktu itu dikarenakan terjadinya masa kemunduran Kaisar Romawi dan Chosroes, krisis politik yang berkepanjangan, intrik persekongkolan dan kontroversi agama, dan ini memudahkan Islam masuk ke wilayah taklukan sebagai penyelamat yang tidak membeda-bedakan status sosial sehingga semua kelompok yang masuk wilayah Islam akan aman $(\mathrm{H}$. Sulasman, 2013: 87 dan Karen Armstrong, 2002: 37). 
Kemenangan kaum muslimin dalam menaklukkan wilayah juga disebabkan oleh adanya gelora semangat, keteguhan, ketabahan, dan keberanian yang ditanamkan oleh pendiri Islam yang suci, Nabi Muhammad Saw., yang telah menanamkan semangat baru itu. Mereka merasa berjuang hanya demi Allah dan dipertajam oleh Umar bin Khattab yang tidak hanya haus kekuasaan dan kemenangan. Dituturkan oleh Al-Waqidi dalam kitabnya Futuh Al Amsha, bahwasanya Umar bin Khattab ra. Berpidato di dalam mesjid, sesudah memanjatkan puji syukur kepada Allah, Umar mengajak dan menganjurkan umat Islam untuk berjihad, kemudian dia mengatakan:

"Sesungguhnya kalian tidak hanya cukup tinggal di Hijaz (Mekah dan Madinah) saja, karena Nabi Saw. pernah menjanjikan kalian menaklukkan negeri Kisra dan Kaisar. Maka berangkatlah kalian ke tanah Parsi." (Muhammad Ahmad Asyur, 1997: 77)

Khalifah Umar memutuskan dua kebijakan pokok pada pemerintahan pasca penaklukan: bahwa pasukan Islam tidak boleh menghancurkan masyarakat pertanian dan harus bekerjasama dengan pimpinan dan kalangan bangsawan wilayah taklukan.
Dalam menjalankan dua kebijakan pokok di atas: Umar melakukan dua prinsip. Pertama, Umar menjadikan pasukan Islam sebagai elite militer yang bertugas menjalankan penaklukan berikutnya, dan untuk membentengi wilayah-wilayah yang sudah ditaklukkan. Pasukan Islam tidak terlibat sebagai pekerja atau profesi dari pekerjaan warga taklukan, juga tidak sebagai pemilik tanah atau sebagai petani. Hal ini dilakukan untuk menghindari terjadinya kerusakan pada tanah-tanah pertanian yang produktif, karena pasukan Islam yang berasal dari Jazirah Arab bukan sebagai petani sehingga mereka tidak terbiasa mengelolah lahan pertanian. Pasukan Islam ditempatkan di perkampunagn militer. Kedua, daerah yang sudah ditundukkan tak boleh warganya diganggu. Ini artinya pasukan Islam tidak boleh memaksakan penduduk setempat untuk memeluk Islam. Nabi Muhammad telah memberikan teladan dengan mengizinkan pemeluk Yahudi dan Kristen di Arabia tetap berpegang pada agama mereka, namun mereka diharuskan membayar upeti, khalifah Umar bin Khattab melanjutkan kebijakan Nabi tersebut dengan memberikan kebebasan beragama terhadap orangorang Yahudi, Kristen, dan Zoroaster Timur Tengah yang mana mereka 
dipandang sebagai ahl al kitab (pemilik kitab suci), yakni pemeluk wahyu tertulis yang terdahulu (Ira M. Lapidus, 1999: 63-64).

Pasukan Islam dalam menaklukkan suatu wilayah, tidak hanya bertujuan mempertahankan eksistensi Islam sebagai agama, tetapi juga mengakui eksistensi agama-agama lain, dan memberi hak kepada warga taklukan yang beragama selain Islam untuk hidup berdampingan dan saling menghormati (M. Quraish Shihab, 2005: 379). Umar bin Khattab memerintahkan pasukan Islam tidak merusak tempattempat ibadah non Islam dan simbolsimbol agama yang mereka sakralkan. Gebernur yang di tempatkan di wilayah yang sudah ditundukkan dilarang untuk melakukan tindakan yang mempersulit warga non Islam dalam menjalankan siar-siar agama mereka. Orang-orang yang hidup di bawah naungan pemerintahan Umar benar-benar terjamin kebebasan akidahnya (Patmawati 2015: 25 dan William Montgomery Watt, 2001: 32).

\section{Dakwah Melalui Pengembangan IImu Pengetahuan dan Pendidikan Agama Islam}

$\begin{array}{lr} & \text { Keberhasilan Umar bin Khattab } \\ \text { dalam melakukan } & \text { ekspansi } \\ \text { menyebabkan terjadinya perpindahan }\end{array}$

orang-orang Jazirah Arab keluar ke wilayah taklukan begitu juga sebaliknya, daerah taklukan melakukan perjalanan ke wilayah jazirah Arab, khususnya bagi mereka yang masuk ke dalam Islam dan mempelajari Islam di Madinah, tempat berkumpulnya para sahabat Nabi. Hal ini yang mendorong Umar untuk membuat tata bahasa Arab agar terhindar dari kesalahan dalam membaca dan memahami Al-Quran dan hadis. Ali bin Abi Thalib adalah pembangun pertama dasar-dasar ilmu nahwu yang selanjutnya disempurnakan oleh Abu AlAswad Al-Du'aly (H. Sulasman, 2013: 94).

Terjadinya perpindahan agama dari non Islam menjadi Islam, sebagian dari mereka ada yang kesulitan memahami maksud dan tujuan dari banyak ayat al-Quran bila tidak dijelaskan dan diterangkan. Terlebih lagi al-Quran hadir dengan tingkatan retorika bahasa tertinggi dan gaya bahasa retorika yang beragama (Muhammad Husain Mahasnah, 2016: 63). Hal ini membuat Umar bin Khattab menganggap perlu menafsirkan ayat alQuran agar terhindar dari kesalahan dalam memahami. Para sahabat yang menekuni penafsiran al-Quran adalah Ubay bin Ka'ab, Abdullah bin Mas'ud, Jabir bin Abdullah al-Anshari, Abu Sa'id al-Khudri, Abdullah bin Zubair, Abdullah 
bin Umar, Anas bin Malik, Abu Hurairah, Abu Musa Al-Asy'ari, dan yang paling terkenal adalah Abdullah bin Abbas. Dalam menafsirkan al-Quran, mereka menggunakan metode mengutip apa yang mereka dengar dari Rasulullah Saw. tentang makna ayat-ayat, yaitu dalam bentuk hadis-hadis yang bersanad (rangkaian orang yang meriwayatkan hadis) (Allamah M.H. Thabathaba'i, 1990: 64). Mereka kemudian dianggap sebagai mufasir pertama dalam Islam.

Para mufassir awal ini sangat memahami al-Quran karena: a. mereka adalah orang yang paling tahu bahasa Arab, yaitu bahasa al-Quran. Selain itu mereka juga orang yang paling mengetahui syair Arab, sastra, serta metode dialog mereka. b. mereka menyaksikan sendiri turunnya al-Quran. Sehingga, mereka tahu sebab turunnya ayat, kesempatan dan kondisi pada saat ayat itu diturunkan. c. selamatnya fitrah mereka, serta betapa kuatnya mereka dalam menyertai Rasulullah, dan antusias dalam mengkaji al-Quran. Inilah yang menjadikan jiwa mereka suci, sesuai dalam menerima pemahaman yang sempurna, ilmu yang benar, dan persepsi nalar yang lurus (Muhammad Husain Mahasnah, 2016: 64).

Dalam memenuhi kebutuhan pendidikan di luar Jazirah Arab, dikirim guru-guru yang terdiri atas para sahabat ahli ilmu, yaitu Abdullah bin Mas'ud dikirim ke Kufah, Abu Musa al-Asy'ari dan Anas bin Malik dikirim ke Basrah, Muadz dan Abu Darda dikirim ke Syam, dan Abdullah bin Amr bin Ash dikirim ke Mesir (H. Sulasman, 2013: 95).

\section{E. Penutup}

Umar bin Khattab adalah sosok yang memiliki gagasan spektakuler, dengan keberanian dan ketegasan telah membawa perubahan yang menyeluruh dalam dunia Islam. Kepribadian yang tegas, otoriter, tetapi berkeadilan, kereligiusannya tidak diragukan, dan orator ulung dimana ceramahnya dapat dilihat dalam buku Pidato-pidato Umar. Dalam penyebaran Islam dilakukan dengan cara ekspansi, pengembangan ilmu pengetahuan dan pendidikan agama Islam.

\section{F. Daftar Pustaka}

Ahmad Hatta dkk., 2005, The Great Story Of Muhammad Saw Rferensi Lengkap Hidup Rasulullah Saw Dari Sebelum Kelahiran Hingga Detik-detik Terakhir, Jakarta: Maghfirah Pustaka.

A Syalabi, 2003, Sejarah dan Kebudayaan Islam I, Jakarta: Pustaka Al-Husna.

Al-Allamah M.H. Thabathaba'i, 1990, Mengungkap Rahasia Al-Qur'an, Bandung: Mizan. 
Badri Yatim, 1993, Sejarah Peradaban Islam, Jakarta: Rajawali Press.

H. Sulasman, 2013, Sejarah Islam di Asia dan Eropa, Bandung: Pustaka Setia.

Ira M. Lapidus, 1999, Sejarah Sosial Umat Islam, Jakarta: Raja Grafindo Persada.

Jaih Mubarok, tt., Sejarah Peradaban Islam, Bandung: Pustaka Bani Quraisy.

Jamil Ahmad, 2000, Seratus Muslim Terkemuka, Jakarta: Pustaka Firdaus.

Karen Armstrong, 2002, Islam Sejarah Singkat, Yogyakarta: Jendela.

Muhammad Ahmad Asyur, 1997, Pidatopidato Umar bin Khattab dan Pesan-pesannya, Bandung: Husaini.

Muhammad Husain Haekal, 2011, Sejarah Hidup Muhammad, Jakarta: Litera AntarNusa.

Muhammad Husain Mahasnah, 2016, Pengantar Studi Sejarah Peradaban Islam, Jakarta: AlKautsar.

M. Quraish Shihab, 2006, Wawasan AlQuran, Bandung: Mizan.
Patmawati, 2014, "Sejarah Dakwah Rasulullah Saw di Mekah dan Madinah" dalam Jurnal AlHikmah, Vol. VIII Edisi 2. --, 2015, "Hubungan Antar Umat Beragama di Masa Nabi Muhammad Saw.", Laporan Penelitian, Pontianak: LP2M IAIN Pontianak.

Philip K. Hitti, 2005, History Of The Arabs, Jakarta: Serambi IImu Semesta.

Syaikh Shaifurrahman Al-Mubarakfury, 2005, Sirah Nabawiyah, Jakarta: Pustaka Al-Kautsar.

Wahyu Ilahi dan Harjani Hefni, 2007, Sejarah Dakwah, Jakarta: Rahmat Semesta.

William Montgomery Watt, 2001, Fundamentalisme Islam dan Modernitas, Jakarta: Raja Grafindo Persada. 